\title{
Arahan Pengembangan Kawasan Sumbing Kabupaten Magelang sebagai Agropolitan
}

\author{
Ellen Deviana Arisadi dan Ema Umilia \\ Jurusan Perencanaan Wilayah dan Kota, Fakultas Teknik Sipil dan Perencanaan \\ Institut Teknologi Sepuluh Nopember (ITS) \\ Jl. Arief Rahman Hakim, Surabaya 60111 Indonesia \\ e-mail: ema_umilia@urplan.its.ac.id
}

\begin{abstract}
Abstrak-Kabupaten Magelang merupakan salah satu kabupaten yang tumbuh dan berkembang dengan konsep agropolitan. Berdasarkan RTRW Kabupaten Magelang Tahun 2010-2030 terdapat 3 kawasan agropolitan di Kabupaten Magelang, salah satunya adalah Kawasan Agropolitan Sumbing. Sejak penerapannya tahun 2011, konsep agropolitan pada kawasan Sumbing dinilai belum memberikan dampak yang signifikan terhadap pertumbuhan ekonomi masyarakat. Hal tersebut terlihat dari masih adanya kesenjangan PDRB antara kawasan perkotaan dan perdesaan. Penelitian ini dimaksudkan untuk merumuskan arahan pengembangan Kawasan Agropolitan Sumbing. Studi dilakukan dengan metode skoring untuk menilai kinerja Kota Tani Utama dan Kota Tani. Hasil yang didapatkan adalah kinerja setiap variabel untuk Kota Tani Utama (KTU Kaliangkrik) dan setiap Kota Tani (KT Bandongan, KT Kajoran, dan KT Windusari). Analisis skoring dilakukan untuk mendapatkan variabel dengan kinerja yang kurang pada setiap KTU dan KT, sehingga dapat dirumuskan arahan untuk meningkatkan kinerja variabel tersebut. Secara umum, arahan untuk Kota Tani Utama Kaliangkrik adalah peningkatan untuk fasilitas pada sektor pemasaran agar dapat berorientasi ekspor, sedangkan arahan pengembangan untuk setiap Kota Tani adalah peningkatan jumlah pelaku industri pengolahan yang disesuaikan dengan komoditas unggulan pada masing-masing wilayah.
\end{abstract}

Kata Kunci-agropolitan, kinerja agropolitan, pengembangan kawasan

\section{PENDAHULUAN}

K ESENJANGAN antara kawasan perkotaan dan perdesaan telah mendorong upaya-upaya pembangunan di kawasan perdesaan. Rencana kawasan agropolitan adalah salah satu upaya mempercepat pembangunan perdesaan dan pertanian, dimana kota sebagai pusat kawasan dengan ketersediaan sumber dayanya, tumbuh dan berkembang mengakses, melayani, mendorong dan menghela usaha agribisnis di desadesa kawasan dan desa-desa sekitarnya (hinterland). Kawasan agropolitan adalah kota pertanian yang tumbuh dan berkembang karena berjalannya sistem dan usaha agribisnis serta mampu melayani, mendorong, menarik, serta menghela kegiatan pertanian agribisnis di wilayah sekitarnya [1].

Kabupaten Magelang merupakan salah satu kabupaten di Provinsi Jawa Tengah yang merupakan penghasil tanaman pangan dan sayuran. Topografinya berupa dataran tinggi sehingga cocok untuk pertanian dan perkebunan. Sesuai dengan kondisi Kabupaten Magelang yang merupakan wilayah agraris, maka pertumbuhan ekonomi Magelang sangat dipengaruhi oleh sektor pertanian. Berdasarkan RTRW Kabupaten Magelang Tahun 2010-2030, Kabupaten Magelang menetapkan kawasan pengembangan agropolitan yang diarahkan pada tiga kawasan, salah satunya adalah Kawasan Agropolitan Sumbing [2]. Kawasan Agropolitan Sumbing mencakup tujuh kecamatan dan ditetapkan empat kecamatan sebagai kawasan inti yaitu Kota Tani Utama (KTU) pada KTU Kaliangkrik dan 3 Kota Tani (KT) yaitu pada KT Bandongan, KT Kajoran, dan KT Windusari [3]. Penerapan konsep agropolitan pada Kawasan Sumbing dimulai sejak tahun 2011, namun hingga kini belum menunjukkan hasil yang optimal. Masih terdapat kesenjangan antar tujuh kecamatan di Kawasan Agropolitan Sumbing dilihat dari PDRB tiap kecamatan [4].

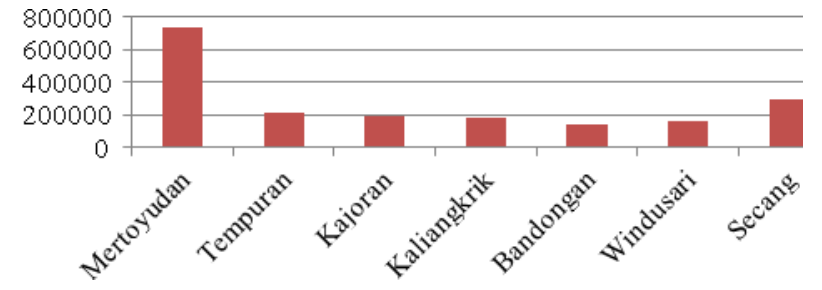

Gambar 1. Grafik PDRB ADHK 2000 Tahun 2012 di Kawasan Agropolitan Sumbing

Sumber: Kabupaten Dalam Angka, 2014

Selain terdapat kesenjangan perekonomian, kurang optimalnya penerapan konsep agropolitan pada Kawasan Agropolitan Sumbing adalah rendahnya kualitas sumberdaya manusia. Pada Agropolitan Sumbing sudah terbentuk kelompok tani di setiap desa, namun banyak diantara kelompok tersebut tidak maksimal/tidak aktif. Dalam upaya menuju pembangunan pertanian yang lebih maju, peran kelembagaan pertanian perlu didorong untuk memberikan kontribusi terhadap proses pembangunan. Kelembagaan pertanian menjadi sebuah penggerak utama untuk mencapai kemajuan pertanian. Kelompok tani menjadi salah satu kelembagaan pertanian yang berperan penting karena kelompok tani merupakan pelaku utama dalam pembangunan pertanian [5].

Sebagai upaya untuk mengembangkan Kawasan Agropolitan Sumbing, diperlukan penelitian mengenai kinerja setiap Kota Tani Utama dan Kota Tani. Melalui penelitian ini akan diketahui variabel apa saja yang memiliki kinerja kurang 
sehingga dapat dirumuskan arahan pengembangan yang sesuai untuk masing-masing wilayah Kota Tani Utama dan Kota Tani sebagai kawasan inti dari Agropolitan Sumbing.

\section{METODE PENELITIAN}

1. Tahapan Penelitian

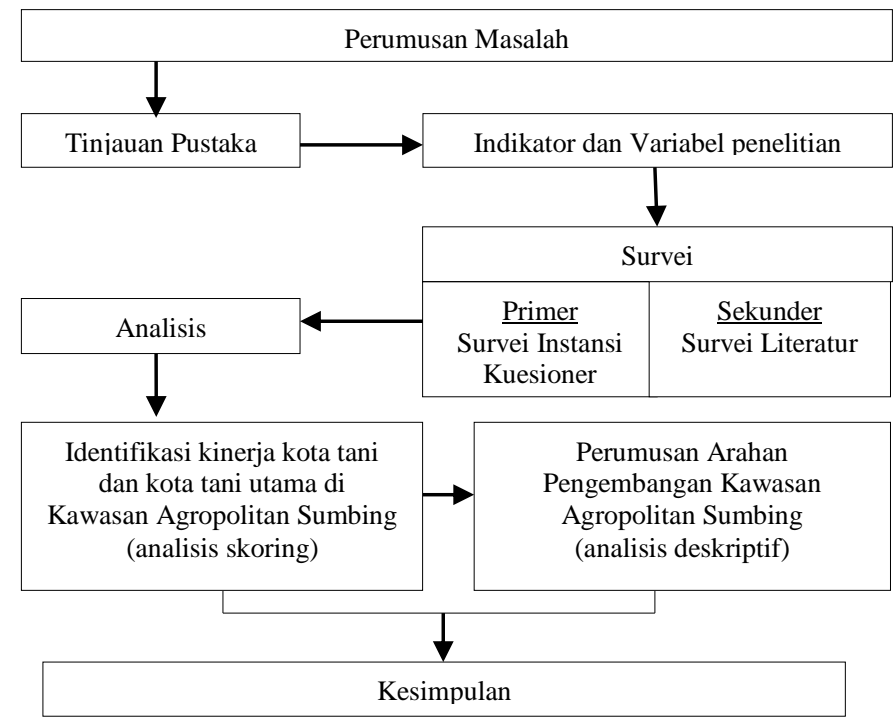

2. Metode Pengumpulan Data

Dalam melakukan pengumpulan data, dilakukan melalui survey primer dan survey sekunder. Survey primer dilakukan dengan melakukan pengamatan lapangan dan menyebarkan kuesioner pada masyarakat petani di Kawasan Agropolitan Sumbing. sementara survey sekunder dilakukan dengan mengumpulkan data-data pendukung yang diperoleh dari instansi-instansi terkait dengan penelitian ini.

\section{Metode Analisis}

Dalam merumuskan arahan pengembangan Kawasan Agropolitan Sumbing, dilakukan melalui dua tahapan analisis. Berikut tahapan analisis yang dilakukan:

\section{A. Mengidentifikasi kinerja Kota Tani dan Kota Tani Utama}

Dalam mengidentifikasi kinerja Kota Tani dan Kota Tani Utama digunakan teknik analisis skoring dengan meninjau variabel penelitian sebagai berikut:

$$
\text { Tabel } 1 .
$$

Variabel Penelitian

\begin{tabular}{llll}
\hline \hline \multicolumn{1}{c}{ Konsep } & \multicolumn{1}{c}{ Indikator } & \multicolumn{1}{c}{ Variabel } \\
\hline Karakteristik & Komoditas & 1. & Jenis Komoditas \\
Agropolitan & Unggulan & 2. & Produktivitas \\
\cline { 2 - 4 } & Jarak pelayanan & 3. & Radius pelayanan \\
& & 4. & Lama Perjalanan \\
\cline { 2 - 4 } & Kegiatan ekonomi & 5. & Industri pengolahan \\
\cline { 2 - 3 } & Daya Dukung & 6. & Jenis Tanah \\
& & 7. & Kemiringan lahan \\
& & 8. & Ketinggian \\
\cline { 2 - 4 } & 9nfrastruktur & 10. & Jaringan jalan \\
& & 11. & Jaringan Irigasi \\
& & 12. & Jaringan air bersih \\
& & 13. & Jaringan Listrik \\
& & 14. & Jaringan Telekomunikasi \\
\cline { 2 - 3 } & Fasilitas & Pasar Umum \\
\hline
\end{tabular}

\begin{tabular}{|c|c|c|}
\hline \multirow[t]{11}{*}{ Konsep } & Indikator & Variabel \\
\hline & & 16. Pasar Khusus \\
\hline & & 17. Fasilitas penyimpanan \\
\hline & & 18. Lembaga swadaya \\
\hline & & $\begin{array}{l}\text { masyarakat agribisnis } \\
\text { 19. Lembaga keuangan }\end{array}$ \\
\hline & & $\begin{array}{l}\text { 20. Lembaga penelitian dan balai } \\
\text { penyuluhan }\end{array}$ \\
\hline & & 21. Forum pengembangan \\
\hline & & $\begin{array}{l}\text { kawasan } \\
\text { 22. Trading house }\end{array}$ \\
\hline & Sumberdaya & 23. Jumlah penduduk \\
\hline & Manusia & $\begin{array}{l}\text { 24. Jumlah penduduk bekerja di } \\
\text { sektor pertanian }\end{array}$ \\
\hline & & 25. Penggunaan Teknologi \\
\hline
\end{tabular}

Sumber: Sintesa Tinjauan Pustaka, 2015

Variabel tersebut digunakan sebagai acuan kuesioner yang akan diberikan kepada responden yaitu masyarakat yang bekerja di sektor pertanian. Setiap variabel diberikan range skor antara 1-3, dimana semakin tinggi skor yang diberikan maka semakin baik kinerja dari variabel tersebut. Pemberian skor tersebut disesuaikan dengan pedoman dan standar terkait untuk setiap variabelnya.

Tabel 2.

Sumber Penilaian Skoring

\begin{tabular}{|c|c|}
\hline Variabel & Sumber \\
\hline Jenis Komoditas & $\begin{array}{l}\text { Pedoman Praktis Pelaksanaan Identifikasi Lokasi, } \\
2006\end{array}$ \\
\hline Produktivitas & $\begin{array}{l}\text { Perhitungan data BPS (Kab. Magelang Dalam } \\
\text { Angka 2014) }\end{array}$ \\
\hline Radius pelayanan & $\begin{array}{l}\text { Pedoman Praktis Pelaksanaan Identifikasi Lokasi, } \\
2006\end{array}$ \\
\hline Lama perjalanan & $\begin{array}{l}\text { Pedoman Praktis Pelaksanaan Identifikasi Lokasi, } \\
2006\end{array}$ \\
\hline $\begin{array}{l}\text { Industri } \\
\text { pengolahan }\end{array}$ & $\begin{array}{l}\text { Judgement Peneliti } \\
\text { berdasarkan data IKM dari Disperinkop dan UMKM } \\
\text { Kab. Magelang }\end{array}$ \\
\hline Jenis tanah & $\begin{array}{l}\text { SK. Menteri Pertanian No. 837/KPTS/UM/11/ } 1980 \\
\text { tentang Kriteria dan Tata Cara Penetapan Hutan } \\
\text { Lindung }\end{array}$ \\
\hline Kemiringan lahan & $\begin{array}{l}\text { SK. Menteri Pertanian No. 837/KPTS/UM/11/ } 1980 \\
\text { tentang Kriteria dan Tata Cara Penetapan Hutan } \\
\text { Lindung }\end{array}$ \\
\hline Ketinggian & $\begin{array}{l}\text { Panduan Evaluasi Kesesuaian Lahan, Balai } \\
\text { Penelitian Tanah dan World Agroforestry Centre, } \\
2007\end{array}$ \\
\hline $\begin{array}{l}\text { Persebaran lahan } \\
\text { pertanian }\end{array}$ & $\begin{array}{l}\text { Peta Penggunaan Lahan Kawasan Agropolitan } \\
\text { Sumbing }\end{array}$ \\
\hline Jaringan jalan & $\begin{array}{l}\text { Pedoman Standar Pelayanan Minimal Bidang } \\
\text { Penataan Ruang, Perumahan dan Permukiman dan } \\
\text { Pekerjaan Umum } \\
\text { (Kepmen Permukiman dan Prasarana Wilayah No. } \\
\text { 534/KPTS/M/2001) }\end{array}$ \\
\hline Jaringan irigasi & $\begin{array}{l}\text { Permen PU No. 32/PRT/ M/ } 2007 \text { tentang Pedoman } \\
\text { Operasi dan Pemeliharaan Jaringan Irigasi }\end{array}$ \\
\hline Jaringan air bersih & $\begin{array}{l}\text { Permen PU No. 14/PRT/M/2010 tentang Standar } \\
\text { Pelayanan Minimal Bidang Pekerjaan Umum dan } \\
\text { Penataan Ruang }\end{array}$ \\
\hline Jaringan listrik & $\begin{array}{l}\text { Judgement Peneliti berdasarkan data sekunder } \\
\text { (RTRW Kab. Magelang Th. 2010) }\end{array}$ \\
\hline $\begin{array}{l}\text { Jaringan } \\
\text { telekomunikasi }\end{array}$ & $\begin{array}{l}\text { Surat Edaran Dirjen Penataan Ruang Kementrian } \\
\text { PU No. 06/SE/ Dr/2011 tentang Petunjuk Teknis } \\
\text { Kriteria Lokasi Menara Telekomunikasi }\end{array}$ \\
\hline Pasar umum & $\begin{array}{l}\text { Permendagri Republik Indonesia No. } 20 \text { Tahun } \\
2012 \text { tentang Pengelolaan dan Pemberdayaan Pasar } \\
\text { Tradisional }\end{array}$ \\
\hline Pasar khusus & Badan Agribisnis Departemen Pertanian,2000 \\
\hline $\begin{array}{l}\text { Fasilitas } \\
\text { Penyimpanan }\end{array}$ & Judgement Peneliti \\
\hline
\end{tabular}




\begin{tabular}{ll}
\hline \hline \multicolumn{1}{c}{ Variabel } & \multicolumn{1}{c}{ Sumber } \\
\hline $\begin{array}{l}\text { Lembaga swadaya } \\
\text { masyarakat }\end{array}$ & Peraturan Menteri Pertanian No. 82/ \\
agribisnis & $\begin{array}{l}\text { Permentan/OT.140/8/2013 tentang Pedoman } \\
\text { Kelompok Tani }\end{array}$ \\
\hline $\begin{array}{l}\text { Lembaga } \\
\text { keuangan }\end{array}$ & $\begin{array}{l}\text { Permentan RI No. 06/Permentan/OT.140/1/2014 } \\
\text { tentang Pedoman Desa Mandiri Pangan Tahun 2014 }\end{array}$ \\
\hline $\begin{array}{l}\text { Lembaga } \\
\text { penelitian dan } \\
\text { balai penyuluhan }\end{array}$ & $\begin{array}{l}\text { Permentan RI No. 06/Permentan/OT.140/2/2012 } \\
\text { tentang Pedoman Kerjasama Penelitian dan }\end{array}$ \\
\hline $\begin{array}{l}\text { Forum } \\
\text { pengembangan } \\
\text { kawasan }\end{array}$ & $\begin{array}{l}\text { Permen PU No. 60/PRT/1991 tentang Persyaratan } \\
\text { Teknis Pembangunan Perumahan Bertumpu pada } \\
\text { kelompok }\end{array}$ \\
\hline Trading house & $\begin{array}{l}\text { Judgement Peneliti didukung oleh keterangan dari } \\
\text { pihak terkait (Bappeda dan masyarakat Sumbing) }\end{array}$ \\
\hline $\begin{array}{l}\text { Penggunaan } \\
\text { teknologi }\end{array}$ & Judgement Peneliti \\
\hline \hline Sumber: Penulis, 2015 &
\end{tabular}

Setiap variabel diujikan pada ke-empat wilayah penelitian, sehingga untuk mengetahui rata-rata skor tiap variabel pada tiap lokasi dilakukan perhitungan rata-rata dengan rumus:

$\bar{X}=\frac{\left(f_{1} \times 1\right)+\left(f_{2} \times 2\right)+\left(f_{\mathrm{g}} \times 3\right)}{\text { Jumlah Responden dalam } 1 \text { Kecamatan }}$

Keterangan:

$\mathrm{f}_{1}$ : frekuensi responden menjawab skor 1

$\mathrm{f}_{2}$ : frekuensi responden menjawab skor 2

$\mathrm{f}_{3}$ : frekuensi responden menjawab skor 3

Setelah mendapatkan skor rata-rata setiap variabel, selanjutnya dilakukan pengukuran kinerja setiap variabel tersebut dengan batasan nilai sebagai berikut :

Kinerja baik : $2 \leq \mathrm{x} \leq 3$

Kinerja kurang : $<2$

Pada penelitian ini skor 1 menunjukkan kondisi yang buruk dan skor 3 menunjukkan kondisi yang baik. Oleh karena itu dapat dikatakan bahwa variabel dengan skor rata-rata semakin mendekati 3 maka kondisinya semakin baik, dan variabel dengan skor semakin mendekati 1 maka kondisinya semakin buruk.

\section{B. Merumuskan arahan pengembangan Kawasan Agropolitan Sumbing}

Untuk merumuskan arahan pengembangan Kawasan Agropolitan Sumbing digunakan metode deskritif dengan melakukan komparasi terhadap hasil analisis skoring dengan kasus pembanding di daerah lain, tinjauan literatur dan kebijakan yang terkait. Dalam menentukan arahan pengembangan juga disesuaikan dengan kondisi eksisting wilayah penelitian.

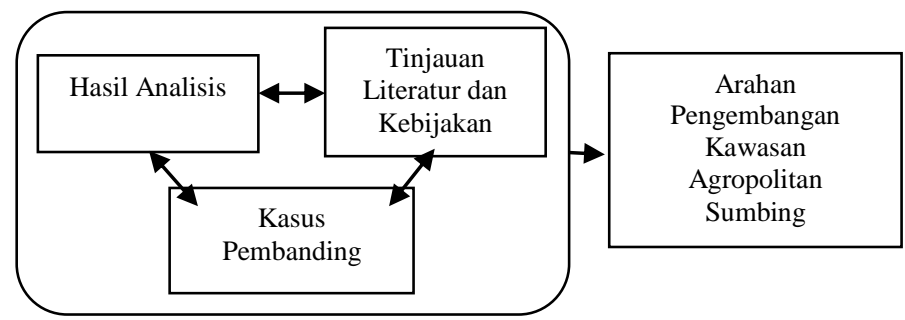

Gambar 2. Analisis Perumusan Arahan Pengembangan Kawasan Agropolitan Sumbing Kabupaten Magelang

Sumber: Penulis, 2015

\section{HASIL DAN PEMBAHASAN}

\section{A. Identifikasi kinerja Kota Tani dan Kota Tani Utama}

KTU Kaliangkrik sebagai pusat dari kawasan agropolitan Sumbing memiliki variabel dengan skor rata-rata yang sebagian besar dengan kinerja baik. Namun skor rata-rata tersebut tidak jauh berbeda dengan skor pada Kota Tani, sehingga dapat dikatakan bahwa kinerja variabel pada KTU Kaliangkrik tidak jauh berbeda dengan kinerja variabel pada Kota Tani lainnya, walaupun pada Kota Tani terdapat lebih banyak variabel yang memiliki kinerja kurang.

KTU Kaliangkrik memiliki 2 variabel yang memiliki kinerja kurang, yaitu trading house dan penggunaan teknologi. Pada kawasan Agropolitan Sumbing belum terdapat trading house, sehingga seluruh responden memberikan skor 1 untuk variabel ini. Sedangkan untuk penggunaan teknologi, pada KTU Kaliangkrik mayoritas petani merupakan petani tradisional yang belum menggunakan teknologi modern dalam kegiatan bertaninya.

Tabel 3.

Komparasi Skor Eksisting Kinerja KTU Kaliangkrik

\begin{tabular}{|c|c|c|c|}
\hline $\begin{array}{l}\text { Indikator / } \\
\text { Kriteria }\end{array}$ & Variabel & $\begin{array}{c}\text { Skor } \\
\text { Eksisting }\end{array}$ & Kinerja \\
\hline Komoditas & Jenis Komoditas & 3,00 & Baik \\
\hline Unggulan & Produktivitas & 2,40 & Baik \\
\hline \multirow[t]{2}{*}{ Jarak Pelayanan } & Radius pelayanan & 2,53 & Baik \\
\hline & Lama perjalanan & 3,00 & Baik \\
\hline Kegiatan Ekonomi & Industri Pengolahan & 2,30 & Baik \\
\hline \multirow[t]{4}{*}{ Daya Dukung } & Jenis tanah & 2,53 & Baik \\
\hline & Kemiringan lahan & 2,53 & Baik \\
\hline & Ketinggian lahan & 2,60 & Baik \\
\hline & Persebaran lahan pertanian & 3,00 & Baik \\
\hline \multirow[t]{5}{*}{ Infrastruktur } & Jaringan jalan & 2,13 & Baik \\
\hline & Jaringan irigasi & 2,23 & Baik \\
\hline & Jaringan air bersih & 3,00 & Baik \\
\hline & Jaringan listrik & 3,00 & Baik \\
\hline & Jaringan telekomunikasi & 3,00 & Baik \\
\hline \multirow[t]{8}{*}{ Fasilitas } & Pasar umum & 2,57 & Baik \\
\hline & Pasar khusus & 2,47 & Baik \\
\hline & Fasilitas penyimpanan & 2,57 & Baik \\
\hline & $\begin{array}{l}\text { Lembaga swadaya } \\
\text { masyarakat agribisnis }\end{array}$ & 2,23 & Baik \\
\hline & Lembaga keuangan & 2,50 & Baik \\
\hline & $\begin{array}{l}\text { Lembaga penelitian dan } \\
\text { balai penyuluhan }\end{array}$ & 2,57 & Baik \\
\hline & Forum pengembangan & 2,63 & Baik \\
\hline & Trading house & 1,00 & Kurang \\
\hline \multirow{3}{*}{$\begin{array}{l}\text { Sumberdaya } \\
\text { Manusia }\end{array}$} & Penggunaan teknologi & 1,53 & Kurang \\
\hline & Jumlah Penduduk & \multicolumn{2}{|c|}{$\begin{array}{c}53.875 \text { jiwa / } 7.814 \\
\text { KK }\end{array}$} \\
\hline & $\begin{array}{l}\text { Jumlah penduduk sebagai } \\
\text { petani }\end{array}$ & \multicolumn{2}{|c|}{37.668 jiwa $(69,9 \%)$} \\
\hline
\end{tabular}

Sumber: Hasil Analisis, 2015

Pada KT Bandongan, komoditas yang menjadi unggulan adalah komoditas padi. Padi Bandongan sudah memiliki brand image di Kabupaten Magelang maupun kabupaten tetangga seperti Kabupaten Wonosobo dan Purworejo. Hal ini juga didukung oleh data dari BPS bahwa luas produksi dan hasil produksi padi di KT Bandongan merupakan yang tertinggi di bandingkan dengan kawasan lainnya di Agropolitan Sumbing.

Berdasarkan hasil analisis skoring, KT Bandongan memiliki 
lima variabel dengan kinerja kurang, yaitu pasar khusus, fasilitas penyimpanan, lembaga penelitian dan balai penyuluhan, forum pengembangan, dan penggunaan teknologi.

Tabel 4.

Komparasi Skor Eksisting Kinerja KT Bandongan

\begin{tabular}{|c|c|c|c|}
\hline $\begin{array}{l}\text { Indikator / } \\
\text { Kriteria }\end{array}$ & Variabel & $\begin{array}{c}\text { Skor } \\
\text { Eksisting }\end{array}$ & Kinerja \\
\hline Komoditas & Jenis Komoditas & 2,05 & Baik \\
\hline Unggulan & Produktivitas & 2,00 & Baik \\
\hline \multirow[t]{2}{*}{ Jarak Pelayanan } & Radius pelayanan & 2,23 & Baik \\
\hline & Lama perjalanan & 2,23 & Baik \\
\hline $\begin{array}{l}\text { Kegiatan } \\
\text { Ekonomi }\end{array}$ & Industri Pengolahan & 2,32 & Baik \\
\hline \multirow[t]{4}{*}{ Daya Dukung } & Jenis tanah & 2,50 & Baik \\
\hline & Kemiringan lahan & 2,45 & Baik \\
\hline & Ketinggian lahan & 2,68 & Baik \\
\hline & Persebaran lahan pertanian & 3,00 & Baik \\
\hline \multirow[t]{5}{*}{ Infrastruktur } & Jaringan jalan & 2,14 & Baik \\
\hline & Jaringan irigasi & 2,18 & Baik \\
\hline & Jaringan air bersih & 3,00 & Baik \\
\hline & Jaringan listrik & 3,00 & Baik \\
\hline & Jaringan telekomunikasi & 3,00 & Baik \\
\hline \multirow[t]{7}{*}{ Fasilitas } & Pasar umum & 2,27 & Baik \\
\hline & Pasar khusus & 1,00 & Kurang \\
\hline & Fasilitas penyimpanan & 1,50 & Kurang \\
\hline & $\begin{array}{l}\text { Lembaga swadaya } \\
\text { masyarakat agribisnis }\end{array}$ & 2,14 & Baik \\
\hline & Lembaga keuangan & 2,27 & Baik \\
\hline & $\begin{array}{l}\text { Lembaga penelitian dan } \\
\text { balai penyuluhan }\end{array}$ & 1,91 & Kurang \\
\hline & Forum pengembangan & 1,95 & Kurang \\
\hline \multirow{3}{*}{$\begin{array}{l}\text { Sumberdaya } \\
\text { Manusia }\end{array}$} & Penggunaan teknologi & 1,64 & Kurang \\
\hline & Jumlah Penduduk & \multicolumn{2}{|c|}{56.156 jiwa } \\
\hline & $\begin{array}{l}\text { Jumlah penduduk sebagai } \\
\text { petani }\end{array}$ & \multicolumn{2}{|c|}{31.950 jiwa $(56,9 \%)$} \\
\hline
\end{tabular}

Sumber: Hasil Analisis, 2015

Pada KT Kajoran telah ditetapkan sebagai kawasan penghasil komoditas unggulan kopi dalam Masterplan Agropolitan Sumbing Tahun 2010. Namun pada kenyataannya, luas produksi dan hasil produksi kopi pada KT Kajoran masih dalam jumlah yang kecil. Pada tahun 2013, komoditas kopi memiliki luas produksi $71 \mathrm{Ha}$ dan jumlah produksi 82 ton. Angka tersebut dapat dibilang kecil apabila dibandingkan dengan luas produksi tanaman perkebunan lainnya di KT Kajoran seperti tembakau (125 Ha) dan kelapa (404 Ha).

Berdasarkan hasil analisis skoring, pada KT Kajoran terdapat 6 variabel yang memiliki kinerja kurang. Variabel tersebut antara lain: industri pengolahan; jaringan irigasi; pasar khusus; fasilitas penyimpanan; forum pengembangan, dan; penggunaan teknologi.

Tabel 5.

Komparasi Skor Eksisting Kinerja KT Kajoran

\begin{tabular}{llcc}
\hline $\begin{array}{c}\text { Indikator } / \\
\text { Kriteria }\end{array}$ & \multicolumn{1}{c}{ Variabel } & $\begin{array}{c}\text { Skor } \\
\text { Eksisting }\end{array}$ & Kinerja \\
\hline Komoditas & Jenis Komoditas & 2,38 & Baik \\
Unggulan & Produktivitas & 2,04 & Baik \\
\hline Jarak Pelayanan & Radius pelayanan & 2,42 & Baik \\
& Lama perjalanan & 2,08 & Baik \\
\hline Kegiatan & Industri Pengolahan & 1,67 & Kurang \\
Ekonomi & & & \\
\hline
\end{tabular}

\begin{tabular}{llcc}
\hline \hline $\begin{array}{c}\text { Indikator / } \\
\text { Kriteria }\end{array}$ & \multicolumn{1}{c}{ Variabel } & $\begin{array}{c}\text { Skor } \\
\text { Eksisting }\end{array}$ & Kinerja \\
\hline Daya Dukung & Jenis tanah & 2,42 & Baik \\
& Kemiringan lahan & 2,42 & Baik \\
& Ketinggian lahan & 2,42 & Baik \\
& Persebaran lahan pertanian & 3,00 & Baik \\
\hline Infrastruktur & Jaringan jalan & 2,08 & Baik \\
& Jaringan irigasi & 1,92 & Kurang \\
& Jaringan air bersih & 3,00 & Baik \\
& Jaringan listrik & 3,00 & Baik \\
& Jaringan telekomunikasi & 3,00 & Baik \\
\hline Fasilitas & Pasar umum & 2,33 & Baik \\
& Pasar khusus & 1,00 & Kurang \\
& Fasilitas penyimpanan & 1,92 & Kurang \\
& Lembaga swadaya & 2,29 & Baik \\
& masyarakat agribisnis & 2,38 & Baik \\
& Lembaga keuangan & 2,08 & Baik \\
& Lembaga penelitian dan & \multicolumn{2}{c}{ Kurang } \\
\hline balai penyuluhan & 1,96 & Kurang \\
& Forum pengembangan & \multicolumn{2}{c}{52.403 jiwa } \\
\hline Sumberdaya & Penggunaan teknologi & & \\
& Jumlah Penduduk & 27.850 jiwa (52,3\%) \\
\hline \hline
\end{tabular}

Sumber: Hasil Analisis, 2015

KT Windusari memiliki komoditas unggulan berupa padi dan tembakau. Tanaman padi dan tembakau pada KT Windusari memiliki produktivitas yang tinggi dibandingkan dengan 3 kawasan lainnya. Namun, berdasarkan data dari Dinas Perindustrian dan UMKM Kabupaten Magelang, jumlah industri pengolahan di Kecamatan Windusari memiliki jumlah terkecil, yaitu sebanyak 23 unit usaha dengan 23 tenaga kerja. Industri tersebut berupa pembuatan tape ketela.

Berdasarkan hasil analisis skoring pada KT Windusari, didapatkan 6 variabel dengan kinerja kurang, yaitu: industri pengolahan; jaringan irigasi; pasar khusus; fasilitas penyimpanan; forum pengembangan, dan; penggunaan teknologi.

Tabel 6.

Komparasi Skor Eksisting Kinerja KT Windusari

\begin{tabular}{llcc}
\hline \hline $\begin{array}{c}\text { Indikator } \\
\text { Kriteria }\end{array}$ & \multicolumn{1}{c}{ Variabel } & $\begin{array}{c}\text { Skor } \\
\text { Eksisting }\end{array}$ & Kinerja \\
\hline Komoditas & Jenis Komoditas & 2,29 & Baik \\
Unggulan & Produktivitas & 2,25 & Baik \\
\hline Jarak Pelayanan & Radius pelayanan & 2,29 & Baik \\
& Lama perjalanan & 2,21 & Baik \\
\hline Kegiatan & Industri Pengolahan & 1,75 & Kurang \\
Ekonomi & Jenis tanah & 2,54 & Baik \\
\hline Daya Dukung & Kemiringan lahan & 2,38 & Baik \\
& Ketinggian lahan & 2,54 & Baik \\
& Persebaran lahan pertanian & 3,00 & Baik \\
\hline Infrastruktur & Jaringan jalan & 2,17 & Baik \\
& Jaringan irigasi & 1,96 & Kurang \\
& Jaringan air bersih & 2,42 & Baik \\
& Jaringan listrik & 3,00 & Baik \\
& Jaringan telekomunikasi & 3,00 & Baik \\
\hline Fasilitas & Pasar umum & 2,33 & Baik \\
& Pasar khusus & 1,00 & Kurang \\
& Fasilitas penyimpanan & 1,83 & Kurang \\
& Lembaga swadaya & 2,21 & Baik \\
& masyarakat agribisnis & 2,25 & Baik
\end{tabular}




\begin{tabular}{llcc}
\hline \hline $\begin{array}{c}\text { Indikator / } \\
\text { Kriteria }\end{array}$ & \multicolumn{1}{c}{ Variabel } & $\begin{array}{c}\text { Skor } \\
\text { Eksisting }\end{array}$ & Kinerja \\
\hline & Lembaga penelitian dan & 2,33 & Baik \\
& balai penyuluhan & 1,92 & Kurang \\
\hline Forum pengembangan & Penggunaan teknologi & 1,42 & Kurang \\
Manusia & Jumlah Penduduk & \multicolumn{2}{c}{48.144 jiwa } \\
& Jumlah penduduk sebagai & 28.303 jiwa $(58,8 \%)$ \\
\hline
\end{tabular}

Sumber: Hasil Analisis, 2015

\section{B. Arahan Pengembangan Kawasan Agropolitan Sumbing}

Hasil analisis pada Tabel 2 - Tabel 5 menunjukkan bahwa pada setiap Kota Tani Utama dan Kota Tani memiliki variabel dengan kinerja kurang. Hal ini menyebabkan Kawasan Sumbing sebagai kawasan agropolitan belum memberikan manfaat yang optimal bagi masyarakat di dalamnya. Sehingga arahan pengembangannya adalah:

Kota Tani Utama Kaliangkrik

1. Meningkatkan kinerja fasilitas, melalui:

a. Meningkatkan kinerja pasar khusus (STA Kaliangkrik) agar dapat berorientasi ekspor dengan membenahi kapasitas kelembagaanya terlebih dahulu.

b. Membangun trading house untuk meningkatkan perekonomian masyarakat pelaku industri pengolahan dan meningkatkan kualitas standar mutu produksi.

c. Mempertahankan dan meningkatkan kinerja fasilitas yang sudah dalam kondisi baik.

2. Meningkatkan kinerja SDM, melalui:

a. Pemberdayaan masyarakat seperti penyuluhan dan pelatihan.

b. Pengadaan pendidikan sekolah lapang, dan

c. Pendirian gedung SMK Pertanian

Kota Tani Bandongan

1. Meningkatkan kinerja kegiatan ekonomi, melalui:

a. Meningkatkan jumlah pelaku industry pengolahan khususnya untuk pengolahan komoditas padi untuk meningkatkan kinerja Kota Tani yang memiliki fungsi sebagai pusat kegiatan agroindustri..

2. Meningkatkan kinerja fasilitas, melalui:

a. Membangun gudang penyimpanan baru pada beberapa desa dan memelihara serta memperbaiki gudang penyimpanan yang sudah ada.

b. Menambahkan jumlah tenaga penyuluh pertanian untuk meningkatkan kinerja lembaga penelitian dan balai penyuluhan.

c. Rutin mengadakan forum diskusi dengan bahasan menarik agar meningkatkan minat masyarakat untuk mengadiri forum dan mendapatkan manfaatnya.

d. Mempertahankan dan meningkatkan kinerja fasilitas yang sudah dalam kondisi baik.

3. Meningkatkan kinerja SDM, melalui:

a. Pemberdayaan masyarakat seperti penyuluhan dan pelatihan.

b. Transfer teknologi agar masyarakat mampu menggunakan dan menghasilkan nilai tambah pada hasil panen mereka.

\section{Kota Tani Kajoran}

1. Meningkatkan kinerja komoditas unggulan, melalui:

a. Perluasan lahan perkebunan kopi untuk meningkatkan produktivitas dan mendukung Masterplan Agropolitan Sumbing untuk menjadikan kopi sebagai komoditas unggulan.

2. Meningkatkan kinerja kegiatan ekonomi, melalui:

a. Mempertahankan dan meningkatkan jumlah pelaku industri pengolahan khususnya untuk komoditas kopi.

3. Meningkatkan kinerja infrastruktur, melalui:

a. Memperbaiki dan memelihara saluran irigasi teknis ataupun non teknis yang sudah ada serta membuar sumur-sumur resapan untuk meningkatkan kinerja jaringan irigasi.

b. Mempertahankan dan meningkatkan kinerja infrastruktur yang sudah dalam kondisi baik.

4. Meningkatkan kinerja fasilitas, melalui:

a. Membangun gudang penyimpanan baru pada beberapa desa dan memelihara serta memperbaiki gudang penyimpanan yang sudah ada

b. Rutin mengadakan forum diskusi dengan bahasan menarik.

c. Mempertahankan dan meningkatkan kinerja fasilitas yang sudah dalam kondisi baik.

5. Meningkatkan kinerja SDM, melalui:

a. Pemberdayaan masyarakat seperti penyuluhan dan pelatihan.

b. Melakukan transfer teknologi.

\section{Kota Tani Windusari}

1. Meningkatkan kinerja kegiatan ekonomi, melalui:

a. Meningkatkan jumlah pelaku industri khususnya untuk komoditas jagung dan tembakau.

2. Meningkatkan kinerja infrastruktur, melalui:

a. Membuat sumur resapan, memelihara dan memperbaiki saluran irigasi teknis dan non teknis yang sudah ada.

b. Mempertahankan dan meningkatkan kinerja infrastruktur yang sudah dalam kondisi baik.

3. Meningkatkan kinerja fasilitas, melalui:

a. Memelihara dan memperbaiki gudang penyimpanan yang sudah ada dan pembangunan gudang penyimpanan pada beberapa desa.

b. Rutin mengadakan forum pelatihan terkait pelatihan untuk penggunaan teknologi budidaya dan pengolahan yang baik khususnya untuk komoditas jagung dan tembakau.

c. Mempertahankan dan meningkatkan kinerja fasilitas yang sudah dalam kondisi baik.

4. Meningkatkan kinerja SDM, melalui:

a. Pemberdayaan masyarakat seperti penyuluhan dan pelatihan.

b. Melakukan Transfer teknologi 


\section{KESIMPULAN/RINGKASAN}

Dari penelitian ini dapat diketahui bahwa KTU Kaliangkrik memiliki kinerja yang lebih baik daripada Kota Tani lainnya. Namun, apabila dilihat dari nilai rata-rata skoring tiap variabel memiliki nilai yang tidak jauh berbeda dengan Kota Tani lainnya, sehingga dapat dikatakan bahwa kinerja KTU hampir sama dengan kinerja KT. Dimana KTU sebagai suatu pusat dari kawasan agropolitan seharusnya memiliki kinerja yang lebih baik di atas KT-nya. Sehingga arahan untuk KTU Kaliangkrik adalah meningkatkan kinerja KTU Kaliangkrik sesuai dengan fungsi utama kota tani utama yaitu sebagai pusat kegiatan pemasaran, dengan cara meningkatkan kinerja STA Kaliangkrik agar berorientasi ekspor dan pembangunan trading house.

Untuk masing-masing Kota Tani memiliki rata-rata 5-6 variabel dengan kinerja yang kurang. Arahan yang diberikan untuk masing-masing Kota Tani adalah sesuai dengan fungsi utamanya sebagai pusat kegiatan agrobisnis. Sehingga arahannya adalah dengan meningkatkan jumlah pelaku industri pengolahan yang disesuaikan dengan komoditas unggulan pada masing-masing wilayah, yaitu padi pada KT Bandongan, Kopi pada KT Kajoran, jagung dan tembakau pada KT Windusari.

\section{DAFTAR PUSTAKA}

[1] Rivai, Deddy Effendi. 2003. "Pengembangan Kawasan Agropolitan Sebagai Pendekatan Wilayah dan Pemberdayaan Masyarakat Pertanian". Sekolah Pascasarjana/S3, Institut Pertanian, Bogor.

[2] Badan Perencanaan Daerah Kabupaten Magelang. 2010. "Rencana Tata Ruang Wilayah Kabupaten Magelang Tahun 2010-2030". Kabupaten Magelang: Pemerintah Daerah Kabupaten Magelang.

[3] Badan Perencanaan Daerah Kabupaten Magelang. 2010. "Masterplan Kawasan Agropolitan Sumbing Kabupaten Magelang Tahun 2010". Kabupaten Magelang: Pemerintah Daerah Kabupaten Magelang.

[4] Badan Pusat Statistik Kabupaten Magelang. 2014. "Kabupaten Magelang Dalam Angka Tahun 2014". Kabupaten Magelang.

[5] Hariadi, S. S. 2011. "Dinamika Kelompok". Sekolah Pascasarjana Universitas Gadjah Mada. Yogyakarta. 